\title{
Impact of Modern Packaging Art on Traditional Aesthetic Ideal
}

\author{
Xiaoli Fan \\ Huanghe Science and Technology College \\ Zhengzhou, China
}

\begin{abstract}
Along with development of market economy, people's living standard is continuously improving, aesthetic idea has changed dramatically, and people have higher requirements for packaging art. Only packaging art has continuous innovation keeping pace with the times and meet people's increasing material and cultural needs. Therefore, innovation is an urgent choice of packaging art.
\end{abstract}

Keywords—-traditional aesthetic ideal; modern packaging art; innovation; humanization; personalization

\section{INTRODUCTION}

The twenty-first century is an open century, with rapid development of knowledge economy and information technology and rapid development of the market economy. Along with rapid development of economy, people's aesthetic level is also continuously developing and people's requirements for life are changing and people have higher requirements for packaging art. If packaging art is to advance with the times and meet people's increasing material and cultural need, it shall have innovation. Innovation is urgent choice of packaging art, to be precise, innovation is the soul of modern packaging art. Therefore, only packaging art abandons traditional aesthetic ideal and has continuous innovation that helps it adapt to social requirements and develop continuously.

Traditional aesthetic ideal is developed surrounding Tai Chi aesthetic culture, Confucian aesthetic culture, Taoist aesthetic culture, and Buddhism aesthetic culture which pursue philosophical thoughts of truth, goodness, beauty and unity of heaven and man. Chinese ancient culture advocates nature and takes nature as beauty, opposes mincement. Chinese are happy and pleased when intoxicated with the nature. Just as Chuang Tse said, "To occupy oneself with the spirit-like operation of heaven and earth", pursue the beauty of tranquility, harmony and nature. However, due to the change of modern aesthetic idea, modern packaging art has higher requirements, meanwhile, modern packaging art has enormous change so as to adapt to social development and further advance aesthetic concept is generated, which has a huge impact on traditional aesthetic ideal. Rationality of traditional aesthetic ideal has unified beauty standards, "gentle and kind", the most idealized works which reach the highest ideal state in China generally reflect one "gentle and simple" artistic style. Chinese traditional aesthetic ideal "gentle and simple" has compatible structure of Confucianism and Taoism, that is, it contains a dynamic state of "engrossed in the real world" advocated by the Confucian and contemplation of "emptiness" and "inaction" advocated by the Taoists. This reflects a tendency of an individual being blended into groups or the nature in Chinese culture's traditional psychology. Confucius said, "Someone who is a clever speaker and maintains a 'too-smiled' face is seldom considered a person of Zen", "What can a man do about the happiness if he is not benevolent?" which fully shows that nature and morality advocated by Confucian is unified. Heaven and human theory of "unity of heaven and man" can be said to be main ideological basis of Chinese traditional culture. However, modern packaging art has diversified tendency, it does not pursue unified aesthetic ideal anymore and attaches importance to personal subjective feeling and personal emotions. It does not take nature as center as before, but has continuous innovation to meet consumer need constantly. Traditional and single enlightenment-type traditional aesthetic consciousness cannot meet modern people's pursuit for packaging art. Humanization and diversification of packaging art has gradually paid attention to by the public.

\section{HuMANIZATION AESTHETIC CONCEPT OF MODERN PACKAGING ART}

Modern aesthetic idea makes higher demands for modern packaging art. Modern packaging art appeals for humanized design. Modern packaging does not only meet use requirements, but also need to consider modern aesthetic trend to meet aesthetic needs of the public. In addition to focusing on visual image of product, Modern packaging art shall pursue inherent characteristics of product and prominent selling point of product, have consideration for consumers from the perspective of consumers and make the product more humanized. It is analyzed from the following three aspects:

So-called humanization, in addition to meet modern aesthetic trend, shall consider the aspects such as packaging materials, packaging structure, modeling and packaging portability and provide convenience for consumers all the time from the perspective of consumers. Firstly, modern packaging materials have broken through traditional single material. Many new-type packaging materials have appeared and provide a wider development road for development of packaging art along with progress of science and technology. Requirements for packaging materials, we shall make different adjustments according to different products, for 
example: for some products with special smell, we shall adopt the method of sealed storage and have higher requirements for packaging materials. Meanwhile, we shall mark product hazard on the packaging, shall notify how to transport, how to use safely, how to store safely, and how to deal with it when an accident happens. We shall take full consideration of consumers and make them feel the happiness of their purchase all the time. Protection of products by modern packaging art is in place, but the used packaging materials shall make proper adjustment according to different objects. For example, for young children's snack packaging, packaging materials meeting children's characteristics shall be adopted. Because children are not strong, easy-open materials shall be adopted; which are convenient for children without parents' help as well as make children develop independent habits and educate them subtly. Secondly, modern packaging art has higher requirements for packaging structure; traditional packaging structure cannot meet consumer demand. Along with change of the public aesthetic idea, packaging structure and modeling also need innovation. In addition to scientificity and rationality of basic structure, beauty, refinement, liveliness and modern artistic smell of modeling shall be paid attention to. Meanwhile, combined with basic knowledge of ergonomics, make design of products in all aspects meet human's own demand and realize that design is served to people invisibly. Take full consideration of users and make people fully realize the fun of modern packaging art. Secondly, portability of packaging shall be carefully considered which consumers are easy to consider when purchasing commodities. Facing with similar products, portable product will be their final choice. Therefore, for heavier products, take full consideration of portability and fully reflect the humanized design philosophy of design serving consumers or the products will lose competitive position on the market. Even if the products are the best, they are not favored by consumers.

Analysis from a visual aspect, facing modern a variety of commodities, if we want to attract consumers' attention, we shall firstly conquer consumers in visual stimulation. Only the commodities with strong visual impact and strong modern sense can form resonance with consumers and be loved and accepted by consumers. These commodities break the traditional, single aesthetic ideal, and do not blindly emphasize harmony and unity of contents and form anymore. In addiction, it does not take realism as the only standard to judge aesthetics while they can reflect the world objectively and meet aesthetic needs of modern packaging art and meet modern peoples' visual experience. They are bold in coloring and break traditional implicit coloring characteristics. Modern packaging art expresses one feeling through vision and accurately and effectively expresses its own feeling through change of color and graphics. For color application in packaging art, different colors carry different cultural information. For example, all natural packaging adopts colors of the nature, mainly green and blue to render one harmonious state. In graphics aspect, through renewed design, brand-new description for the nature meets aesthetic requirements of modern art.
Along with rapid development of communication technology, communication and human connection become more and more remote due to development of modern communication tools. Human interaction is growing indifferent and people become significantly more lonely. Therefore, people need more caring and consideration. This psychological need just reflects on modern packaging art. Graffiti art fully reflects this point in application of packaging art. As one reflection of personal state of mind, graffiti fully shows the demand deep in heart and closes the distance with customers and easy to make consumers to purchase, which fully reflects humanized design of packaging art.

\section{PeRsonalized AESTHetic CONCEPT OF MODERN PACKAGING ART}

Personalization is one tendency of modern packaging art. In modern packaging art, we advocate bold innovation and packaging designers shall meet the mental and emotional demand of modern people at all levels, take risks to seek new breakthroughs and create a packaging style applicable for product from various angles to meet demand of a wide variety of consumers. Personalized packaging design is popular with the young generation. It has no fixed form and breaks through various traditional constraints, which fully reflect the young generation's strong desire to seek change and innovation, characteristics of unwillingness to be restrained, psychological characteristics of daring to break constraint of reality and seeking free life. The young generation's aesthetic concept promotes development of the whole packaging art and reflects characteristics of modern society. Seeking change and innovation becomes a constant theme and personalized aesthetic concept has been popular with people. Similar design must be eliminated. Only personalized design seeking change and innovation is what people want which can keep pace with the times and not be abandoned by people. Personalized packaging art has made different analysis for different groups and also made different analysis for all levels of groups. Personalized packaging art is targeted; everyone has his own aesthetical standard. Therefore, personality pursued by them is also different and formed styles are different. Then the designer needs to make deep observation, design different packaging according to different groups, and take full consideration of consumers demand to get recognition of consumers.

Modern society is one society pursuing personalization. The idea of "people oriented" has been popular with people. Modern packaging art serves people and shall meet people's needs in different aspects. Personalized design is to meet people's psychological needs. Along with rapid development of modern society, people's attention to others is on the decline and men are becoming strangers. The intimacy before is continually transfiguring into indifference due to social development. In this situation, people need more attention from others, but in modern society, if people want to be paid attention to, personalization is a necessary choice, which is exactly the same with personalization of packaging art. Only distinctive and personalized packaging art can possess vitality and not be eliminated. 
Personalization of packaging art focuses on innovation, which requires the designer to possess advanced ideas if he desires to have continuous innovation to make packaging art walk in the front of times and lead the fashion. Sticking to tradition cannot generate innovation and even cannot create personalized packaging art. Only if we constantly break through traditional law constraint and make continuous innovation and break through ourselves, learn more foreign innovative ideas, think more, do more, observe and consider constantly, cultivate inspiration more can we create brand new packaging form; which is refreshing and accepted by the public. Personalization of packaging art is always a full reflection of creative thought. Only when we take a road not taken by others can we create a distinctive packaging art image. Qi Baishi once said, "The one who learn from me will have a bright future, but those who imitate me will wither away". This requests the designer has his own design characteristics, but not stays in the predecessors' basis. Only we bring forth the new through the old, take our own roads can we design packaging art works with unique personality. In order to design works with unique personality, sometimes we need to constantly deny ourselves and break through ourselves, then our packaging art can show unique charm.

\section{Times Aesthetic CONCEPT OF MODERN PACKAGING ART}

Our current era has entered one information era with highly developed science and technology. The things we could not imagine many years before have now come true. Especially, earth-shaking changes appear since our country implemented reform and opening policies. Much advanced culture and technology in the world has constantly been introduced to our country and gradually used by us to promote rapid development of our country. Ideology of seeking change and innovation is shared by all mankind. Only by doing these can we promote social development. Therefore, faced with the fast developing society, sticking to tradition is absolutely not allowed. We must keep up with the times, constantly breaking up traditional constraint and bring forth the new through the old can we create packaging art works with infinite vitality and new artistic conception which are favored by modern people. In packaging art, firstly, we shall adopt composition, different tradition, break the routine, make bold attempts to use different and peculiar composition, observe more, dare to break through various constraints and give a wide space for composition. In packaging art, owing one excellent composition is the half of success. Secondly, we shall also carefully consider font design in packaging art. Properly using the words with modernity can close distance with consumers and can be accepted by consumers easily. Meanwhile, we can use English alphabets, Chinese phonetic alphabets or various deformed art fonts, such as pop font, to provide a brand new aesthetic feeling. This may encourage people to get rid of the constraint of traditional, silly rules and regulations and in one relaxed and happy environment, feel the beauty of modern packaging art and feel the emotional involvement of modern packaging art.

We shall realize that although traditional aesthetic ideal has long-term accumulation, faced with current fast developing society, it is impracticable to request modern packaging art through traditional aesthetic ideal. Modern packaging art needs to relate to people's lives. Current popular social elements are fully reflected in packaging art.

\section{CONCLUSION}

Packaging art has no fixed form to conform to. Along with times development, people's ideas are also changing constantly. Only packaging art that keeps pace with the times and breaks through antiquated tradition can meet people's increasing material and cultural needs, meet people's aesthetic needs and fully realize the idea of packaging art serving the people heart and soul.

\section{REFERENCES}

[1] Wang Anxie. Visual Design of Package Image [M]. Nanjing: Southeast University Press, 2006

[2] Ouyang Chaoying. Package Creativity [M]. Nanjing: Wuchang: Hubei Fine Arts Publishing House, 2003

[3] Han Ying. Package Image [M]. Shanghai: Shanghai Joint Publishing Press, 2007

[4] Yang Renmin. Package Design [M]. Chongqing: Southwest China Normal University Press, 1998

[5] Lu Ying. History and Aesthetics of Visual Communication Design. Beijing: China Renmin University Press, 2000 